\title{
Prison officers' views about hepatitis C testing and treatment: A qualitative enquiry
}

\section{INTRODUCTION}

Hepatitis $\mathrm{C}$ virus ( $\mathrm{HCV}$ ) is a blood borne viral infection and is a leading cause of liver disease in the UK (National Institute for Health and Care Excellence, 2012). The principal route by which $\mathrm{HCV}$ is transmitted in the UK is injecting drug use. In England, Scotland and Wales the prevalence of HCV antibodies amongst people who inject drugs (PWID) was found to be $49 \%, 53 \%$ and $33 \%$ respectively (Public Health England, 2013). PWID are imprisoned frequently, with more than $40 \%$ having at least five episodes of incarceration (Health Protection Agency, 2012).

The prevalence of all blood borne viruses (BBV) amongst prisoners in the U.K. has not been rigorously established due to the paucity of testing which occurs. Public Health England (2014) reported that only $7.8 \%$ of people newly admitted to prisons were tested for HCV in 2013. A recent study in all 14 Scottish prisons found $19 \%$ of the overall population were positive for $\mathrm{HCV}$ antibodies and 53\% amongst these had a history of injecting drugs (Taylor, Munro, Allen et al., 2013). In response to this, a tripartite agreement between The National Offender Management Service, NHS England and Public Health England (NHS, 2013) introduced an 'opt-out' approach to HCV testing in prisons from April 2014 with an aim of substantially increasing the rates of testing and diagnosis. An opt-out strategy involves testing for BBVs routinely as part of a standardised clinical examination (Basu, Smith-Rohrberg, Hanck et al. 2005) during the first week of imprisonment, compared to the currently used opt-in approach whereby prisoners are screened for BBVs only if they agree when the test is offered to them. 
The effective screening and treatment of prisoners involves services provided by a multidisciplinary team. Prison Custody Officers (PCOs) act as the interface between the prisoner and health services and can contribute to the wellbeing of offenders by assisting in observations and interventions. As noted by Dvoskin and Spiers (2004), PCOs are the experts on the prison environment and have the greatest understanding of the day to day realities that may affect prisoners' health aside from the prisoners themselves; hence it is both relevant and important to explore their responses. Furthermore, the views of those who work with prisoners have been identified as under-researched and constitute a gap in the literature by the National Institute for Health and Care Excellence (2012). In particular, PCOs views on hepatitis C testing and treatment have not been explored qualitatively in the international literature. Against this background, a qualitative research study was undertaken in an East Midlands category B male prison with the aim of exploring the views of PCOs about prisoners being tested and treated for HCV.

\section{METHODOLOGY}

The study was conducted using an interpretive framework of enquiry, that of phenomenology, and sought to make sense of 'the lived experience' of PCOs. Interpretive methodology is directed at understanding from an individual's perspective, investigating interaction among individuals as well as the historical and cultural contexts which people inhabit (Creswell, 2009, p.8). Individual constructs are elicited and understood through interaction between the researcher and participant (Guba \& Lincon, 1994, p.111) and is of the moment and subject to interpretation. Research is deemed good if it provides rich evidence and offers credible and justifiable accounts of the phenomenon under investigation (Richie \& Lewis, 2003, p. 263-286; Cohen et al, 2007, p. 133-149). 
This is also seen as one of its weaknesses as findings cannot be generalised and are of limited use when devising policy lacking as it does transferability. Such an approach does however offer an insight into the experience of those involved and provides both an understanding and basis on which to develop further studies.

\section{Data collection and analysis}

Interpretive theory is usually grounded (inductive), being generated from the data, (Cohen et al., 2007, p.22) and therefore offers a snapshot into otherwise contested realities. Because of this the research question tends to be broad and seeks to illuminate something not fully understood or explored. The aim of the researcher was to capture and describe as accurately as possible the phenomenon under investigation and to give voice to the experiences of those taking part in the study.

In keeping with the chosen methodology face-to-face semi-structured interviews were conducted in sterile offices within the prison, which are areas designated as being prisoner-free. The interviews were conducted during July and August 2014.

Purposeful sampling was used in the selection of the participants. The sample was based on the researchers access to potential participants and the purpose of the research, seeking to interview participants who "had experiences relating to the phenomenon to be researched" (Kruger, 1988 p.150) and who were prepared to participate in the study. Ten PCOs were recruited, eight men and two women, who had between 4 and 16 years of experience in their role. Questions were "directed to the participant's experiences, feelings, beliefs and convictions about the theme in question" (Welman \& Kruger, 1999, p.196) and the interviews typically lasted between 40 minutes to an hour. 
The participants were reminded prior to the interview of their rights to anonymity but that any information which could compromise the integrity of the prison security regime or was about illegal activity would have to be reported. The interviews were audio-recorded and transcribed verbatim at the prison.

In keeping with the methodology adopted a process of thematic analysis was used to analyse the transcripts of the interviews. Braun and Clarke's (2006) thematic analysis framework proved a useful guide to the analysis and involved coding, (open, axial, and selective), categorising and organisation of themes, and included the following stages:

1. Familiarisation with the data.

2. Generating initial codes.

3. Searching for themes.

4. Reviewing and refining themes.

5. Defining and naming themes.

Braun and Clarke (2006) stress that the 'keyness' of a theme is not necessarily dependent on quantifiable measures, but rather on whether it captures something important in relation to the overall research question.

Throughout the process of analysis the researcher sought to immerse herself with the data in order to ensure a thorough account of the emerging themes. Phenomenology is grounded in the belief that the researcher and the participants come to the investigation with fore-structures of understanding shaped by their respective backgrounds, and in the process of interaction and interpretation, they cogenerate an understanding of the phenomenon being studied (Woinar \& Swanson, 2007, pp. 175). 
Interpretivists acknowledge that value free knowledge is not possible. For example, researchers assert their beliefs when they choose what to research, how to research and how to interpret their data (Edge \& Richards, 1998, p. 336) and it is likely that analysis will challenge pre-existing understanding and knowledge of the subject under investigation. The researcher has experience of treating prisoners with HCV both in prison and hospital environments, and of testing for all blood borne viruses in primary care and community drug clinics. The findings presented illuminate the differences in worldviews held between those working in a custodial environment and the researcher's position as a health-care professional, resonating with Newbold, Ross, Jones et al.'s (2014) assertion that "prisons are emotionally provocative".

\section{Ethics}

Research ethical approval was obtained from the prison's Research Ethics Committee (REC). National Offender Management REC approval was not required for this study as the prison in which this research was conducted is a privately run establishment and the research involved staff rather than prisoners.

\section{FINDINGS}

Four key interconnected themes emerged: Safeguarding, Stigma, Confidentiality and Education.

\section{Safeguarding}

The need to safeguard the prison's security regime, coupled with ensuring the safety of prisoners and staff was the dominant theme to emerge. The health and wellbeing of prisoners was considered secondary except in cases of emergency. 
Typical responses were,

"the issue with the health should be considered, if it's not life threatening ... then security should be the priority".

And

"you can't treat 'em 'till we get the security right. You just cannot."

This meant that PCOs would sometimes question a prisoners' request to see the medical team.

"they will somehow get themselves placed on medical hold because they don't want to leave here, it's [medical hold] a ball-ache, because we have got some that are playing the system"

The PCOs were generally supportive of an opt-out approach to HCV testing of prisoners, "Yes, I think that's a really good idea", although some could see a flaw in offering this:

"It should become mandatory....otherwise what's the point? If 10 prisoners are gonna opt-out, them 10 could infect another 10 who then don't know they've got it.....just seems to defeat the object really"

It was evident that the risk of acquiring a BBV whilst carrying out their duties was a concern to PCOS

"if he'd been self-harming maybe and he had hep and there was blood everywhere I'd be thinking, 'oh gosh, am I going to catch this?' " 


\section{Stigma}

Stigma was the second key theme to emerge from the interviews, with the majority of PCOs identifying that HCV infection was a taboo subject amongst the prisoners:

"there's one on our wing, he was quite embarrassed by it [HCV] so he told everyone he had cancer"

And

"It dictates their association circles as well so if they thought that someone had something they could contract something from, it would dictate which group they hang with".

Many participants suggested that the source of the stigma was HCV's association with intravenous drug use:

"the method of how they got the hep C...there's probably a lot of drug use which carries a stigma also doesn't it?"

Visits to hospital out-patients clinics were also described as a source of stigma that deterred some prisoners from wanting to continue to engage with HCV treatment:

"and it's always that stigma when you walk in [to a hospital clinic], people look, 'oh my God it's a prisoner'".

\section{Confidentiality}

The rights of prisoners to expect confidentiality about health issues including their HCV status was widely acknowledged by the PCOs, for example:

"confidential, nothing to do with anybody else apart from healthcare and the individual" 
However, it was clear that some prisoners may forgo their right to privacy:

"some that are refractory, they'll scream and shout from the rooftops 'I've got hep C, just you wait I'll do this, that and the other to you' ".

If a prisoner states that they are HCV positive, this can create a dilemma for PCOs in deciding whether to share this information, For example:

"if a prisoner told me that he'd got hep C, I'd probably keep it to myself because I have seen other members of staff be prejudiced against people because of what they've done".

However, the PCO's potential exposure to body fluids when intervening in an altercation prompted an alternative view:

"Would I tell somebody, a close friend if I knew they were in contact? Possibly, yeah".

Several PCOs asserted that they wished to use the confidential knowledge about a prisoner's HCV positive status to protect other prisoners:

"There's a lad, got a set of hair clippers and he'd lend it to two or three others on the wing while he had hepatitis, and you just feel like going up to them and giving them a nudge and saying 'listen you really shouldn't be using those shears', but we can't" 


\section{Education}

All of the PCOs knew that HCV is transmitted via sharing drug injecting paraphernalia but were less clear about other modes of transmission and the consequences of infection, for example:

"is $C$ the one that can be passed on through saliva and stuff like that?"

A few believed that HCV is airborne :

"we did have a prisoner on the wing who had it and we had to implement some safeguards, he had to wear a mask"

Several knew that sharing hair clippers might transmit HCV:

"it's now 5 or 10 prisoners on a wing have a set of hair clippers, I doubt they're cleaned how they should be".

Prison tattooing was identified by most PCOs as a high risk activity:

"to have a tattoo and know the consequences then it's self-harming"

Many of the PCOs knew nothing about the long-term consequences of HCV infection:

"The long term effects of it? I don't know, is it kidneys or liver?"

Although access to HCV treatment in prison was viewed favourably by most PCOs, some participants expressed internal moral dilemmas

"if it was a prisoner or somebody on the out who's always paid his National Insurance, never done a crime in his life then I'm sorry I'd have to say that person [not the prisoner] would get it in favour of that person [the prisoner]. 
All of the PCOs said that they did not have enough training about HCV:

"training or anything like that? No, don't think I've ever had any. You might get some on hep B cos of the vaccines"

This lack of information was identified as the cause of anxiety following-incidents such as a prisoner self-harming:

"If their [PCOs] understanding was little better, perhaps the panic wouldn't be so bad, y'know 'I've got a bit of blood on my skin, oh Christ I must have it now' and y'know phone calls up to healthcare, every single ailment, 'oh my God, oh my God, I'm not sleeping' "

\section{DISCUSSION}

The main finding to emerge from this enquiry was that the PCOs have insufficient knowledge about HCV, which underpins and fuels the further emergent themes of safeguarding, stigma and confidentiality.

\section{Safeguarding}

It was evident from the perspectives on Safeguarding that the PCOs have a multifaceted role of enforcing the prison regime and ensuring the security of the prison, whilst simultaneously looking after the prisoners and each other. It was clear that all security issues will override those pertaining to health unless there was an immediately life threatening situation. A prisoner's need to complete a course of medical treatment was deemed irrelevant if the individual in question was found in possession of a mobile phone or drugs. 
Although the public health guidance produced by the National Institute for Health and Care Excellence (2012) requests that prisoners are placed where possible on medical hold to ensure continuity of treatment, the PCO's view was that hospital-led health care should be seamless and work around the prison system, rather than risk the prison security being weakened and impede the flow of prisoners across the prison simply to enable attendance at a hospital appointment.

$\mathrm{HCV}$ testing and treatment was viewed positively and considered a good use of prisoners' time so they could re-engage with families and employment upon release without having to cope with the side effects of a course of antiviral therapy. Furthermore, all of the participants agreed that HCV treatment did not cause any practical prisoner management problems on the wing. This positive perspective could be channeled to encourage more prisoners to engage in HCV related healthcare for instance by openly talking about the benefits of accessing treatment whilst in prison.

\section{Stigma}

It was anticipated that stigma might be raised as an issue given that $\mathrm{HCV}$ is a stigmatising disease (Treloar, Rance, Backmund et al., 2013). For example, people who are drug or alcohol dependent are sometimes labelled 'difficult' and moral judgements can be passed on those whose diagnosis may be viewed as their own fault (MacDonald, 2003). Some participants did indicate during the interviews that as HCV infection can be self-inflicted, sympathy towards the prisoners is reduced.

The PCOs are in a unique position to influence both the development of stigma and its' dissipation through their interactions with the prisoners. 
For example, the description of a prisoner with HCV having to wear a face-mask may have added to the stigmatisation of HCV on the prison wing, and thus negatively impacted upon others' decisions about receiving anti-viral treatment (Geppert and Arora, 2005). Khaw, Stobbart and Murtagh (2007) and Yap, Carruthers, Thompson et al. (2014) identified that the stigma of other prisoners knowing that an individual was infected was a barrier to HCV testing. Thus the narrative heard in this study of how prisoners form associations with each other through shared experiences on the prison wing, including the types of health-care accessed, illustrates how those identified through observation as receiving HCV treatment may be stigmatised and rejected by other social clusters.

\section{Confidentiality}

A consistent theme heard throughout the interviews was that the PCOs concerns about their personal safety and risk of exposure to a BBV could potentially compromise the prisoners' confidentiality. However, as all the PCOs expressed a desire to know who was infected so they could take steps to mitigate risk during incidents of violence or self-harm, it could be that the motivation for being supportive of testing prisoners was for their own health protection rather than the prisoners' health needs. This finding echoes that of Perrett, Erricker and Lyons (2014) who found that $31 \%$ of prison officers believed that prisoners should disclose their hepatitis status to the prison staff.

Prisoners' concerns about confidentiality not being maintained were highlighted by Khaw et al (2007) who qualitatively explored the factors that influence prisoners' uptake of HCV testing and found that this fear deterred some prisoners from being tested. 
In this study some PCOs explained that prisoners who divulged having HCV enabled "caring" conversations to take place, whilst others used their infective status as a threat. Thus health related confidentiality, one of the few rights a prisoner has, may be a commodity to be traded in exchange for positive social contact on the prison wing or as a tool with which to try and gain an advantage.

\section{Education}

This theme perhaps holds the key to developing interventions which may increase prisoners' uptake of HCV testing and subsequent treatment via a change in the prison culture.

For example, had adequate education been available for both staff and prisoners there would not have been any requirement for the prisoner with HCV to wear a face mask thus abating the PCO's safety fears, plus the prisoner would not have been subjected to stigmatising actions and their confidentiality may have been maintained. It is possible too that understanding $\mathrm{HCV}$ transmission risks may negate the need to breach prisoner-as-patient confidentiality regarding any blood-borne virus (BBV) infections.

Perrett et al. (2014) found that completion of a BBV e-module resulted in increased knowledge. In contrast however, Dillon and Allwright (2005) found that PCOs who had received $\mathrm{BBV}$ training did not have an increased knowledge of their transmission routes or any reduction in anxiety regarding personal risks. Lloyd, Clegg, Lange et al. (2013) found that a lack of HCV related knowledge amongst prison staff constituted a barrier to $\mathrm{HCV}$ testing and treatment uptake, so the universal insufficiency of HCV knowledge revealed amongst the PCOs interviewed in this study will be important to address. The nature of the training materials is perhaps the key to PCOs having confidence in their knowledge and this warrants further exploration. 


\section{CONCLUSION}

This study is the first qualitative enquiry to the authors' knowledge into the views of prison custody officers about HCV. The primary purpose of this study, to elicit PCOs' views about prisoners being tested and treated for $\mathrm{HCV}$, has been achieved, revealing the PCOs' previously unheard voice and bringing to light four key, highly interdependent themes. All of the PCOs interviewed were in favour of prisoners receiving $\mathrm{HCV}$ testing and treatment and richly described the context in which this occurs; principally that security of the prison environment, the prisoners and the staff necessarily transcends health. Furthermore this study further illustrates that the potential organisational difficulties which stem from the need to blend research Good Clinical Practice principles with security requirements when conducting health-care research in a prison can be overcome.

As Clemmer first noted back in 1940, the prison is a self-contained world that is vastly different from the rest of society that prisoners. The PCOs hold the keys to both the literal and metaphorical gates that facilitate access to healthcare and thus have an untapped potential to act as health promoters. The question is however, if the paradigm shift required to enable this would ever be feasible. 


\section{References}

Basu,S., Smith-Rohrberg, D., Hanck,S. and Altice,F.L. (2005) HIV Testing in Correctional Institutions: Evaluating Existing Strategies, Setting New Standards. AIDS and Public Policy Journal 20(1/2): pp. 3-24.

Braun, V. and Clarke, V. (2006) Using thematic analysis in psychology. Qualitative Research in Psychology 3: pp.77-101.

Clemmer,D. (1940). The Prison Community. Boston: Christopher

Cohen L, Manion L \& Morrison K (2007) Research methods in education (6 ${ }^{\text {th }}$ Ed.). London: Routledge Falmer.

Creswell J W (2009) Research Design. Qualitative, Quantitative, and Mixed Methods Approaches ( $3^{\text {rd }}$ Ed.) London; Sage.

Dillon and Allwright. (2005) Prison Officers' Concerns About Blood Borne Viral Infections. Howard Journal of Criminal Justice 44(1): pp.29-40.

Dvoskin, J.A. and Spiers, E.R. (2004) On the Role of Correctional Officers in Prison Mental Health. Psychiatric Quarterly (75)1: pp.41-59.

Edge J \& Richards K (1998). May I see your warrant please? Justifying Outcomes in Qualitative research. Applied Linguistics 19 (3): 334-356 
Geppert, C.M.A. and Arora, S. (2005) Ethical Issues in the Treatment of Hepatitis C. Clinical Gastroenterology and Hepatology 3: pp.937-944.

Guba E G \& Lincoln Y S (1994). Competing paradigms in qualitative research. In N K Denzin \& Y S Lincoln (Eds.) Handbook of qualitative research pp. 105-117. Thousand Oaks, CA; Sage.

Health Protection Agency and Health Protection Services prison Network (2012) Health Protection Services 2012 Standards for HPUs in relation to HP in Prisons, 2012. [online] Available at:

http://webarchive.nationalarchives.gov.uk/20140714084352/http://www.hpa.org.uk/ webc/HPAwebFile/HPAweb C/1317135290134 (Accessed 21.12.2015)

Khaw, F-M., Stobbart, L., Murtagh, M. (2007) 'I just keep thinking I haven't got it because I'm not yellow': a qualitative study of the factors that influence the uptake of hepatitis C testing by prisoners. BMC Public Health (7): pp.98-104.

Kruger, D. (1988). An introduction to phenomenological psychology (2nd edn.). Cape Town: Juta.

Lloyd, A., Clegg, J., Lange, J., Stevenson, A., Post, J., Lloyd, D., Rudge, G., Boonwaat, B., Forrest, G., Douglas, J., Monkley, D. (2013) Safety and Effcetiveness of a Nurse-Led Outreach Programme for Assessment and Treatment of Chronic Hepatitis C in the Custodial Setting. Clinical Infectious Diseases Advance Access January 29.

MacDonald, M. (2003) Seeing the Cage. Stigma and Its Potential to Inform the Concept of the Difficult Patient. Clinical Nurse Specialist 17(6): pp.305-30. 
NHS England (2013) National Partnership Agreement Between: The National Offender Management Service, NHS England and Public Health England for the Co-Commissioning and Delivery of Healthcare Services in Prisons in England. NHS England Publications Gateway Reference 00435 [online]. Available at: http://www.justice.gov.uk/downloads/about/noms/work-with-partners/nationalpartnership-agreement-commissioning-delivery-healthcare-prisons2013.pdf [Accessed 8 June 2015].

Newbold G., Ross I J., Jones RS., Richards SC., Lenza M (2014) Prison Research from the Inside: The Role of Convict Autoethnography Qualitative Inquiry April 20: pp.439-448.

National Institute for Health and Care Excellence (2012) Public Health Guidance 43: Hepatitis B and C: ways to promote and offer testing to people at increased risk of infection [online]. Available at: http://www.nice.org.uk/guidance/ph43 [Accessed 8 June 2015].

Perrett SE, Erricker M, Lyons M. (2014) Evaluation of an e-learning package to improve understanding of blood-borne viruses amongst prison staff in Wales, UK. International Journal of Prisoner Health 10(1): pp.47-54.

Public Health England (2014). Local Authority Liver Disease Profiles Nottingham [online]. Available at: http://www.endoflifecare-intelligence.org.uk/profiles/liverdisease/E06000018.pdf [Accessed 8 June 2015] 
Public Health England (2013) Shooting Up: Infections among

people who inject drugs in the United Kingdom 2012 [online]. Available at:

https://www.gov.uk/government/publications/shooting-up-infections-among-peoplewho-inject-drugs-in-the-uk [Accessed 8 June 2015].

Ritchie J \& Lewis J (Eds.) (2003) Qualitative Research Practice. A Guide for

Social Science Students and Researchers. London; Sage.

Taylor, A., Munro, A., Allen, E., Dunleavy, K., Cameron, S., Miller, L. and Hickman,M. (2013) Low incidence of hepatitis C virus among prisoners in Scotland. Addiction 108(7): pp. 1296-304.

Treloar, C., Rance, J., Backmund, M. (2013) Understanding Barriers to Hepatitis C Virus Care and Stigmatization from a Social Perspective. Clinical Infectious Diseases 57 (Suppl.2): S51-S55.

Welman and Kruger 1999

Wojnar D.M. and Swanson K. M. (2007) Phenomenology: An Exploration. Journal of Holistic Nursing 25 (3): pp.172 - 180.

Yap, L., Carruthers, S., Thompson, S., Cheng, W., Jones, J., Simpson, P., Richards, A., Thein, H-H., Haber, P., Lloyd, A., Butler, T. (2014) A Descriptive Model of Patient Readiness, Motivators and Hepatitis C Treatment Uptake among Australian Prisoners. PLOS ONE (9)2: pp.1-11. 